\title{
PROGRESSIVE REDUCTION OF TOLVAPTAN DOSES IN THE TREATMENT OF CHRONIC SIADH
}

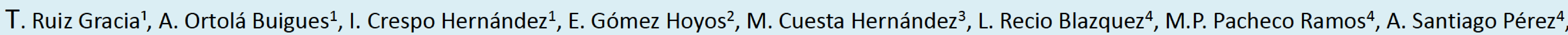
A.L. Calle Pascual ${ }^{1}$, I. Runkle de la Vega ${ }^{1 .}$

1Servicio de Endocrinología y Nutrición. Hospital Clínico San Carlos, Madrid, España. 2Servicio de Endocrinología y Nutrición. Hospital Clínico de Valladolid, Valladolid, España. 3Endocrinology Department, Beaumont Hospital, Dublin, Ireland. ${ }^{4}$ Servicio de Farmacia. Hospital Clínico San Carlos, Madrid, España.

INTRODUCTION:

Chronic tolvaptan (TV) therapy has been found to be safe and effective in the treatment of chronic SIADH. However, the experience with modification of doses over time is limited.

\section{MATERIAL AND METHODS:}

We conducted a retrospective analysis of weekly TV doses $(\mathrm{mg})$ in 41 patients with chronic SIADH treated for a minimum of 3 months, seen a week following discharge and monthly thereafter. Serum sodium (SNa) goal was $137-140 \mathrm{mmol} / \mathrm{L}$, with $50 \%$ TV dose reduction when $\mathrm{SNa} \geq 141$ and increase when $\mathrm{SNa}<137$. SNa in $\mathrm{mmol} / \mathrm{L}$ corrected for glycemia/ total proteins. Kruskal-Wallis, Mann-Whitney U, SPSS15.

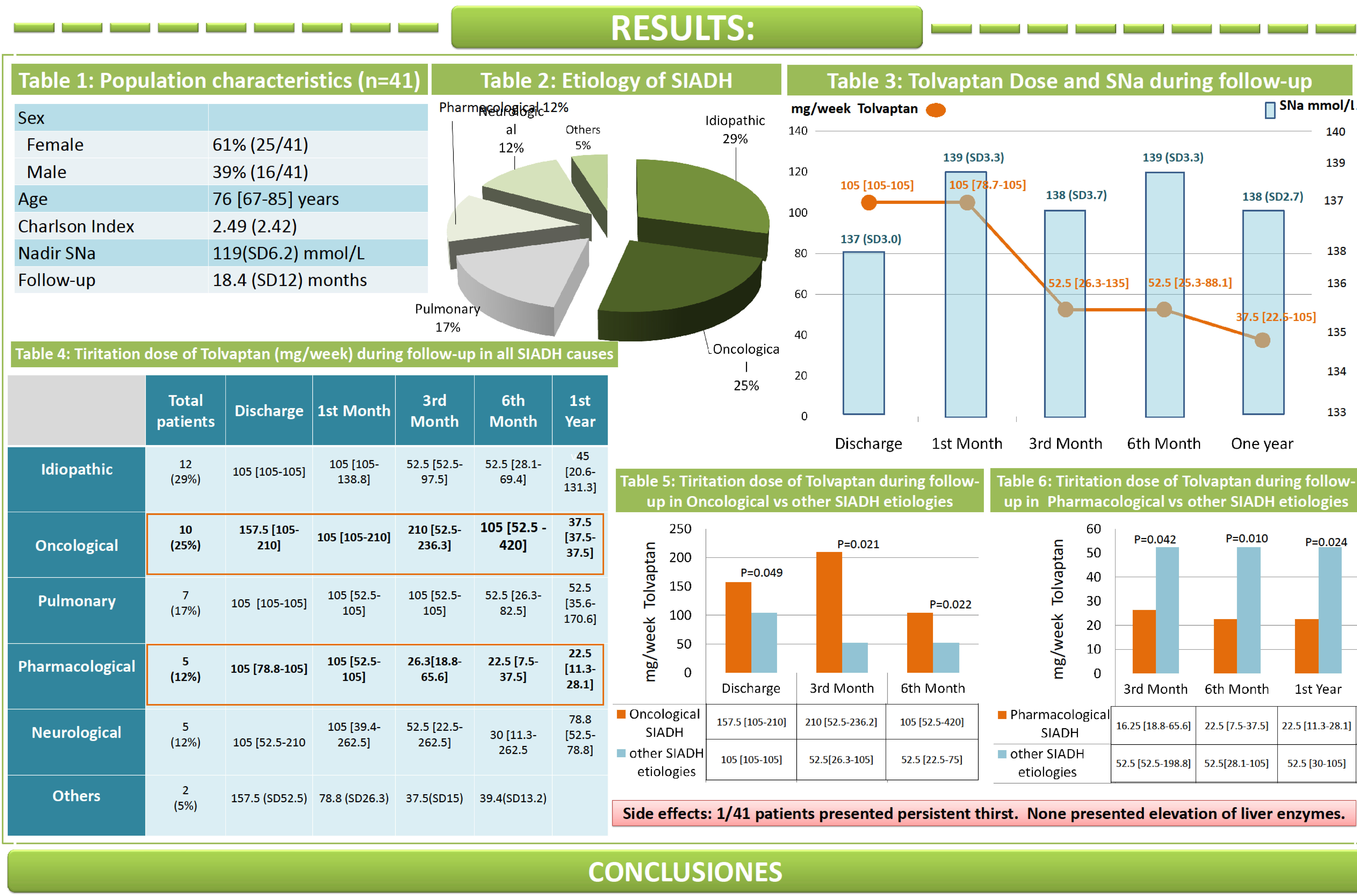

Chronic tolvaptan therapy is safe and can maintain strict eunatremia in patients with chronic SIADH. Progressively lower doses are needed, thus contributing to economic sustainability of therapy. The minimum dose is usually attained after 6 months of therapy. Oncological patients require higher doses, and pharmacological patients lower ones.

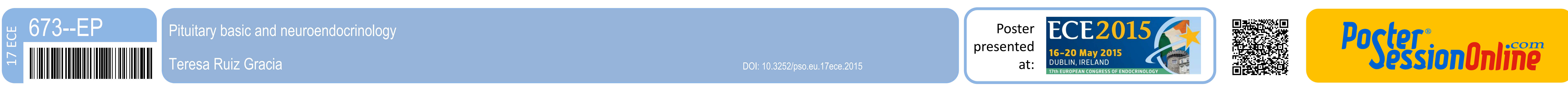

